\title{
Obstetric hysterectomy: a retrospective study
}

\author{
Savita N. Kamble, Yuga M. Jamdade* \\ Department of Obstetrics and Gynecology, B. J. Government Medical College, Pune, Maharashtra, India
}

Received: 29 September 2021

Revised: 01 November 2021

Accepted: 02 November 2021

\section{*Correspondence:}

Dr. Yuga M. Jamdade,

E-mail: yugajamdade14@gmail.com

Copyright: ( $)$ the author(s), publisher and licensee Medip Academy. This is an open-access article distributed under the terms of the Creative Commons Attribution Non-Commercial License, which permits unrestricted non-commercial use, distribution, and reproduction in any medium, provided the original work is properly cited.

\begin{abstract}
Background: Obstetric hysterectomy $(\mathrm{OH})$ is last resort usually opted to save life of a mother in critical obstetric conditions compromising her reproductive potential. With increasing caesarean deliveries incidence of morbidly adhered placenta is increasing, thus increasing need of $\mathrm{OH}$. We aimed to study socio-demographic factors, incidence, indications, complications and feto-maternal outcomes associated with obstetric hysterectomy. Also, we aimed to study factors which affect the maternal and fetal outcome in obstetric hysterectomy case so as to minimize maternal and neonatal mortality and morbidity.

Methods: We conducted a retrospective analytical study of 2 years 6 months in Department of Obstetrics and Gynecology at a tertiary and teaching institute of western Maharashtra.

Results: The incidence of obstetric hysterectomy was 0.4\%. Majority of women were between 25-35 years age group and parity two or more. Most common indication was postpartum haemorrhage (PPH) (41.1\%) followed by uterine rupture $(29.4 \%)$ and adhered placenta $(23.5 \%)$. Most common risk factor found was previous caesarean delivery. Most common complication was need of intensive care unit (ICU) and vasopressor support.

Conclusions: Proper antenatal care, screening for high-risk obstetric cases and registration of those patients at a wellequipped hospital and early referral and delivery at tertiary hospital by expert surgeon with timely decision, timely and adequate transfusions can prevent maternal and fetal complications.
\end{abstract}

Keywords: Adhered placenta, Obstetric hysterectomy, Postpartum haemorrhage, Uterine rupture

\section{INTRODUCTION}

Obstetric hysterectomy $(\mathrm{OH})$ is defined as removal of the uterus either at the time of caesarean section or following vaginal delivery, or within the puerperium period. It is usually performed in the face of unrelenting and lifethreatening obstetric hemorrhage. The incidence of obstetric hysterectomy is 1:30,000 when after vaginal delivery whereas it is 1:1700 when after a caesarean delivery, 1: 220 if it is after 2 or more caesarean deliveries. ${ }^{1}$ Caesarean hysterectomies are most commonly performed to arrest or prevent hemorrhage from intractable uterine atony or abnormal placentation. ${ }^{2}$ Other indications for obstetric hysterectomy are traumatic $\mathrm{PPH}$, uterine rupture, postpartum uterine sepsis in which case postpartum infection from an infected uterus, necrotic uterus requires uterine removal for recovery, intractable uterine inversion. Rare causes include cervical neoplasia, ovarian neoplasia. The higher rates of hysterectomy and associated morbidity are more often found in low-resource setting, but severe maternal morbidity is common in wellequipped hospitals. Indeed, emergency obstetric hysterectomy is a universal marker of severe acute maternal morbidity (SAMM) ${ }^{3,4}$ Multiple pregnancy has been shown to have a two to eight fold increased risk of hysterectomy, compared with singletons. ${ }^{5,6}$ Because of increasing rates of both caesarean sections and assisted reproductive technology induced multifetal pregnancy, the incidence of emergency obstetric hysterectomy is likely to increase worldwide. ${ }^{7,8}$ It is important to study such events since they provide an insight into the standard of care 
provided and help to reduce maternal morbidity and mortality.

Conservative methods such as use of misoprostol, oxytocin in the prefilled auto-disable drug delivery systems, condom catheter balloon, and non-inflatable antishock garments for the management of hypovolemic shock have all been advocated to effectively manage obstetric hemorrhage in low resource settings. Advances in interventional radiology have also provided the option of uterine artery embolization.

While this does seem encouraging, with regard to clinical implications, hemorrhage continues to be the leading individual cause of maternal death worldwide accounting for $27.1 \%$ of deaths. ${ }^{9}$ In one analysis, India and Nigeria together accounted for a third of global maternal deaths. ${ }^{9}$ More alarming is the fact that some studies from developed nations are pointing towards an increase in the rate of postpartum hemorrhage. ${ }^{10}$ One meta-analysis reported an annual increase of $8 \%$ in the incidence of $\mathrm{OH}$ around the world. ${ }^{11}$

In spite of all these advances obstetric hysterectomy is necessary sometimes to save the life of mother. Obstetric hysterectomy is associated with increased risk of intraoperative complications and massive blood loss which itself poses mother at high maternal morbidity and mortality. Timely decision and good surgical skills help to reduce maternal morbidity and mortality.

We aimed to evaluate incidence, age and parity distribution, indications, associated antenatal risk factors and complications associated with $\mathrm{OH}$.

\section{METHODS}

This hospital-based retrospective, analytical study was carried out in one unit of the department of obstetrics and gynaecology, B. J. Government Medical College and Sassoon General Hospitals, Pune from January 2018 to June 2020.

\section{Inclusion criteria}

Women who underwent obstetric hysterectomy post normal delivery or caesarean section during study period were included in the study. Also, women who delivered outside the hospital but referred to for obstetric complications and warranting obstetric hysterectomy were also included.

Accordingly, a total of 17 eligible women who fulfilled the selection criteria were retrospectively enrolled. Prior to the commencement, permission was obtained from Department of Medical records to retrieve the data.

The data was retrieved and evaluated for age, parity, mode of delivery, indication for obstetric hysterectomy, risk factors in antenatal or intranatal period, antenatal care
(ANC), whether registered at same hospital or referred from other hospital and for feto-maternal outcome.

\section{Statistical analysis}

The data obtained was coded and entered into Microsoft Excel Worksheet. The data was analysed using statistical software SPSS version 20.0. The data was expressed in terms of numbers and percentages.

\section{RESULTS}

\section{Incidence}

Out of total 4041 deliveries during our study period there were total 17 patients who underwent obstetric hysterectomy, incidence being $0.4 \%$. Four cases out of 2829 vaginal deliveries $(0.14 \%)$ and 13 cases out of 1212 caesarean deliveries $(1.07 \%)$ required $\mathrm{OH}$ (Table 1$)$.

Table 1: Incidence of obstetric hysterectomy.

\begin{tabular}{|llll|}
\hline Type of delivery & $\begin{array}{l}\text { Total no. } \\
\text { of patients }\end{array}$ & OH & $\begin{array}{l}\text { Incidence } \\
(\%)\end{array}$ \\
\hline $\begin{array}{l}\text { Normal vaginal } \\
\text { delivery }\end{array}$ & 2829 & 04 & 0.14 \\
\hline Cesarean section & 1212 & 13 & 1.07 \\
\hline Total & 4041 & 17 & 0.4 \\
\hline
\end{tabular}

\section{Age and parity}

Maximum patients, 10 out of 17 (58.8\%) were between 25 to 35 years age group, there were 2 patients $(11.8 \%)$ below 20 years and 2 patients $(11.8 \%)$ above 35 years age. There were $7(41.2 \%)$ multipara patients, $6(35.2 \%)$ patients were second para and 4 (23.5\%) were primipara (Table 2 ).

Table 2: Age and parity.

\begin{tabular}{|c|c|c|c|c|c|c|}
\hline \multirow{2}{*}{$\begin{array}{l}\text { Age in } \\
\text { years }\end{array}$} & \multicolumn{4}{|c|}{ Parity } & \multirow{2}{*}{ Total } & \multirow{2}{*}{ Percentage } \\
\hline & 1 & 2 & 3 & 4 & & \\
\hline 18- 20 & 1 & 1 & & & 2 & 11.7 \\
\hline $20-25$ & 1 & 1 & 1 & & 3 & 17.6 \\
\hline $25-30$ & 2 & 2 & 1 & & 5 & 29.4 \\
\hline $30-35$ & & 1 & 3 & 1 & 5 & 29.4 \\
\hline $35-40$ & & 1 & & 1 & 2 & 11.7 \\
\hline Total & 4 & 6 & 5 & 2 & 17 & \\
\hline
\end{tabular}

\section{Indications}

The most common indication was postpartum haemorrhage. There were 3 patients of traumatic PPH and 4 patients of atonic PPH which required obstetric hysterectomy, incidence being $41.2 \%$. Second most common indication was ruptured uterus; there were 5 (29.4\%) patients of ruptured uterus who required obstetric hysterectomy. Other indications were morbidly adhered placenta 4 patients $(23.5 \%)$ and puerperal sepsis 1 patient (5.9\%) (Table 3). 
Table 3: Indications for obstetric hysterectomy.

\begin{tabular}{|c|c|c|}
\hline Indications & Number & Percentage \\
\hline \multicolumn{3}{|l|}{ Postpartum haemorrhage } \\
\hline \multicolumn{2}{|l|}{ Traumatic PPH } & \multirow{3}{*}{17.6} \\
\hline $\begin{array}{l}\text { Intracesarean extension of } \\
\text { uterine incision }\end{array}$ & 7 & \\
\hline $\begin{array}{l}\text { Perforation during surgical } \\
\text { evacuation of pregnancy }\end{array}$ & 2 & \\
\hline Atonic PPH & 1 & \multirow{4}{*}{23.5} \\
\hline Abruption placentae & 1 & \\
\hline Placenta previa & 1 & \\
\hline Uterine atony & 2 & \\
\hline \multicolumn{3}{|l|}{ Ruptured uterus } \\
\hline Caesarean Scar rupture & 4 & \multirow[b]{2}{*}{29.4} \\
\hline $\begin{array}{l}\text { Secondary to perforation in } \\
\text { previous pregnancy }\end{array}$ & 1 & \\
\hline Morbidly adhered placenta & 4 & 23.5 \\
\hline Puerperal sepsis & 1 & 5.88 \\
\hline
\end{tabular}

\section{Risk factors}

Most of the patients who underwent $\mathrm{OH}$ had more than one risk factor. Most common risk factor was previous caesarean delivery, there were $6(35.3 \%)$ patients with prior 1 caesarean delivery and $2(11.8 \%)$ with previous 2 caesarean deliveries. Thus, out of total 17, eight (47.05\%) patients had previously scarred uterus. Another most common risk factor was multiparity $(41.2 \%)$. Other risk factors were morbidly adhered placenta; there were 4 $(23.5 \%)$ patients with adhered placenta, abruptio placentae $(11.8 \%)$, severe preeclampsia $(23.5 \%)$, unregistered $(17.5 \%)$, home delivery $(11.8 \%)$, placenta previa $(5.9 \%)$ and underlying medical disorder $(5.9 \%)$. There was only one patient with no risk factor who required obstetric hysterectomy for atonic PPH (Table 4).

Table 4: Associated risk factors.

\begin{tabular}{|lll|}
\hline Obstetric risk factor & Number & Percentage \\
\hline Previous 1 caesarean section & 6 & 35.3 \\
\hline Previous 2 caesarean section & 2 & 11.8 \\
\hline Placenta previa & 1 & 05.8 \\
\hline Adhered placenta & 4 & 23.5 \\
\hline Abruptio placentae & 2 & 11.8 \\
\hline Severe pre-eclampsia & 4 & 23.5 \\
\hline Home delivery & 2 & 11.8 \\
\hline Nil & 1 & 05.9 \\
\hline
\end{tabular}

Table 5: Delivery place.

\begin{tabular}{|lll|}
\hline Place & Number & Percentage \\
\hline Delivery at present institute & 11 & 64.7 \\
\hline Delivery outside hospital & 6 & 35.3 \\
\hline
\end{tabular}

Five patients were delivered before admission, out of that 5 , two patients were delivered at home by unskilled birth attendant and 3 were hospital deliveries. Both two patients who delivered at home were unregistered (Table 5).

Table 6: Referral status.

\begin{tabular}{|lll|}
\hline Referral status & Number & Percentage \\
\hline Referred & 14 & 82.4 \\
\hline Not referred & 3 & 17.6 \\
\hline
\end{tabular}

Fourteen $(82.4 \%)$ patients were referred. Our institute being tertiary hospital maximum patients was referred (Table 6).

Table 7: Registration status.

\begin{tabular}{|lll|}
\hline Registration status & Number & Percentage \\
\hline Registered & 14 & 82.4 \\
\hline Unregistered & 3 & 17.6 \\
\hline
\end{tabular}

There were $14(82.4 \%)$ registered patients and $3(17.6 \%)$ unregistered patients (Table 7).

Table 8: Feto-maternal complications.

\begin{tabular}{|lll|}
\hline Complications & Number & Percentage \\
\hline Maternal & & \\
\hline Fever & 2 & 11.8 \\
\hline Coagulopathy & 5 & 29.4 \\
\hline Wound infection & 1 & 05.9 \\
\hline Need of vasopressor & 12 & 70.6 \\
\hline ICU admission & 14 & 82.4 \\
\hline Mortality & 5 & 29.4 \\
\hline Fetal & & \\
\hline NICU admission & 1 & 05.9 \\
\hline Mortality & 7 & 41.2 \\
\hline
\end{tabular}

\section{DISCUSSION}

Obstetric hysterectomy has always been and will always be nightmare scenario for obstetrician. Though maternal morbidity and mortality is increased while obstetric hysterectomy, it is lifesaving procedure. Decision of obstetric hysterectomy is end of the road measure, so obstetrician must be hundred percent sure that it is the only answer.

Incidence of obstetric hysterectomy in our study was $0.4 \%$, which is comparable to $0.38 \%$ reported by Sinha et al and $0.39 \%$ reported by Chew and Biswas et al. ${ }^{12,13}$ This is higher than $0.32 \%$ reported by Mantri et al and $0.18 \%$ reported by Kore et al. ${ }^{14,15}$ Most of our patients were between 25 to 35 years age group (58.8\%). Seven out of $17(41.1 \%)$ patients were para 3 and para 4. High association with multiparity was also noted by Najam et al, Bhat et al, and Singh et al. ${ }^{16-18}$ There were four primipara patients in whom $\mathrm{OH}$ was needed at the cost of her reproductive potential. Out of these 4, two patients were delivered by caesarean at outside hospitals, one was 
unmarried and unregistered primigravida with severe preeclampsia, abruption placenta, intrauterine fetal demise (IUD) and the last patient was primigravida without any risk factor delivered vaginally and went into atonic PPH. In all these patients a mother's life and their reproductive potential could have been preserved would have been patient registered, thoroughly evaluated to diagnose complications at early stage and termination at precise timing and at the hands of expert gynaecologist had done.

Most common indication in our study was postpartum haemorrhage $(41.2 \%)$, there were 3 patients with traumatic PPH and 4 patients with atonic PPH. Out of the three traumatic PPH patients two were delivered by caesarean section at outside hospital, laparotomy done for hemoperitoneum and one was illegal abortion done at home presented with traumatic PPH with bowel injury. Out of 4 atonic PPH patients one was abruption placentae and one was placenta previa, 2 patients had uterine atonicity not responding to medical treatment. Second commonest indication was ruptured uterus $(29.4 \%)$ out of which 4 patients had previous caesarean section and one patient had history of uterine perforation in previous surgical termination of pregnancy procedure. Morbidly adhered placenta was also one of the major indications accounting for $23.5 \%$ of total patients. Similar findings were reported by Bhat et al, Kant et al and Agashe et al. ${ }^{17,19,20}$ Previous caesarean section was most common risk factor found in our study. There were 6 patients with previous one caesarean section and two patients had previous 2 caesarean sections. Danger combination of previous caesarean section and morbidly adhered placenta was found in $17.6 \%$. Similar association of previous caesarean delivery and adhered placenta was reported by Bhat et al, Bakshi et al, Francois et al. ${ }^{17,21,22}$ Other risk factors were severe preeclampsia $(23.5 \%)$, unregistered status $(17.6 \%)$, home delivery $(11.8 \%)$. Out of 4 severe preeclampsia patients one was unmarried prim gravida with severe preeclampsia with most dreaded complications HELLP and irreversible DIC. Another patient was also combination of severe preeclampsia with HELLP and DIC, obstetric hysterectomy done along with internal iliac artery ligation because oozing through vault. Internal iliac artery ligation was also required in 3 more patients, two patients were previous LSCS with uterine rupture with broad ligament hematoma, and one patient was previous LSCS with placenta percreta. So total 4 patients required internal iliac artery ligation, one patient required bladder repair and one patient underwent resection anastomosis for bowel. Thus $35.3 \%$ patients required additional surgeries. Operative morbidity was due to condition for which Obstetric hysterectomy was performed and not due to operative procedure.

As ours is tertiary institute 14 out of $17(82.4 \%)$ were referred from outside hospital. This again proves importance of early detection and timely referral of highrisk patients to avoid obstetric morbidity and mortality. Three out of $17(17.6 \%)$ were unregistered and six out of $17(35.3 \%)$ were delivered before admission to our hospital, out of those 2 were home delivered, one was illegal abortion done at home presented with traumatic PPH and bowel injury and another one was home delivered by local dais presented on postpartum day 10 with puerperal sepsis. These two patients could have been avoided had it been the hospital delivery. Three were outside caesarean section presented with hemoperitoneum. Last patient was delivered at rural hospital with history of previous caesarean section, presented with uterine rupture.

Most common complication found in our study was need of ICU admission in $82.4 \%$ and vasopressor support postoperatively in $70.6 \%$ patients, this high rate was observed because maximum patients were referred from outside hospital in critical condition or shock, as ours is the only tertiary hospital catering both urban and rural area in district. Incidence of maternal mortality found to be $29.4 \%$ which is very high compared to similar studies, Singh et al $1.96 \%$, Bhat et al $04 \%$, Sinha et al $6.01 \%$, Mantri et al $14 \% .^{12,14,17,18}$ It was found to be comparable to study by Allahabadia et al $32 \% .^{23}$ Incidence of maternal mortality was high because maximum patients were referred very late in condition of shock and DIC, which even hysterectomy could not save life of a mother, highlighting the importance of golden hour management of catastrophic obstetric events.

Fetal complications were NICU admission in $5.9 \%$ patients and intrauterine fetal demise seen in $41 \%$ patients, which was because of conditions requiring obstetric hysterectomy like abruption placenta and ruptured uterus.

This study had several limitations that is, the results of this study were based on the retrospective data from a single centre with relatively smaller sample size. Hence these findings need to be interpreted cautiously. Another important limitation was inclusion of referral cases leading to the recall bias which would have effect on the quality of information especially while evaluating the data of risk factors in antenatal or intranatal period as well as feto maternal outcome.

\section{CONCLUSION}

With the increasing incidence of caesarean deliveries and morbidly adhered placenta, need of obstetric hysterectomy is increasing. With the improvement of modern obstetrics and newer modalities for treatment of PPH and adhered placenta, incidence of obstetric hysterectomy is reduced. However, it will never completely disappear from obstetric practice, because we cannot guarantee that all these conservative measures will be successful in all patients. Also, its incidence can be reduced by providing good antenatal care, identification of risk factors and timely intervention at well-equipped hospital. Identification of risk factors and timely referral to tertiary facility can prevent obstetric hysterectomy in many patients. Previous caesarean section was the most common risk factor found in our study hence measures to reduce caesarean section rates especially in primigravidas must be considered so as 
to prevent the consequences like adherent placenta and rupture uterus. Mass education and timely counselling of patients for contraception and sterilization can prevent unwanted pregnancies and their complications.

Funding: No funding sources

Conflict of interest: None declared

Ethical approval: The study was approved by the Institutional Ethics Committee

\section{REFERENCES}

1. Shellhaas CS, Gilbert S, Landon MB, Varner MW, Leveno KJ, Hauth JC, et al. The frequency and complication rates of hysterectomy accompanying cesarean delivery. Obstet Gynecol. 2009;114(2 Pt 1):224.

2. Bateman BT, Mhyre JM, Callaghan WM, Peripartum hysterectomy in the United States: nationwide 14-year experience. Am J Obstet Gynecol. 2012;206(1):63. e1-8.

3. Baskett TF. Epidemiology of obstetric critical care. Res Clin Obstet Gynecol. 2008;22:763-74.

4. Baskett TF, O’Connell CM. Severe obstetric maternal morbidity and mortality: 15 yearspopulation-based study. J Obstet Gynecol. 2005;25:7-9.

5. Walker MC, Murphy KE, Pan S, Yang Q, Wen SW. Adverse maternal outcome in multifetal pregnancies. BJOG. 2004;111(11):1294-6.

6. Baskett TF, O'Connell CM. Maternal critical care in obstetrics. J Obstet Gynecol Can. 2009;31(3):218-21.

7. Wen SW, Huang L, Liston RM, Haeman M, Baskett TF, Rusen ID. Severe maternal morbidity in Canada, 1991-2001. Can Med Assoc J. 2005;173:759-63.

8. Kwee A, Bots ML, Visser GHA, Bruinse HN. Emergency peripartum hysterectomy: a prospective study in the Netherlands. Eur. J Obstet Gynecol Reprod Biol. 2006;124(2):187-92.

9. Say L, Chou D, Gemmill A, Tuncalp O, Moller AB, Daniels J, et al. Global causes of maternal death: a WHO systematic analysis. Lancet Glob Health. 2014;2(6):e323-33.

10. Cameron CA, Roberts CL, Olive EC, Ford JB, Fischer WE. Trends in postpartum haemorrhage. Aust NZJ Public Health. 2006;30(2):151-56.
11. Tuncalp O, Hindin MJ, Souza JP, Chou D, Say L. The prevalence of maternal near miss: a systematic review. BJOG. 2012;119(6):653-61.

12. Sinha HH, Mishra MG. Hysterectomy for obstetric emergencies J Obstet Gynecol India. 2001;51:111-4.

13. Chew S, Biswas A. Caesarean and postpartum hysterectomy. Singapore Med J. 1998;39:9-13.

14. Mantri L, Maheswari K, Kiran C. Emergency hysterectomy. A 10 years review. J Obstet Gynecol India. 1993;43:936-9.

15. Kore S, Potwar S, Tamboli J. Obstetric hysterectomy: analysis of 34 cases. J Obstet Gynecol India. 2001;51:111-4.

16. Najam R, Bansal P, Sharma R, Agrawal D. Emergency obstetric hysterectomy: a retrospective study at a tertiary care hospital. J Clin Diagn Res. 2010; 4:2864-8.

17. Bhat $S$, Bhave $S$. Obstetric hysterectomy a lifesaving procedure and its complications. Int J Med Dent Sci. 2016;5(1):996-1000.

18. Singh R, Nagrath A. Emergency obstetric hysterectomy- a retrospective study of 51 cases over a period of 5 years. J Obstet Gynecol India. 2005;55(5):428-430.

19. Ankita K, Kavita WW. Emergency obstetric hysterectomy. J Obstet Gynecol India. 2005;55(2):132-4.

20. Agashe AP, Marathe SS. Obstetric hysterectomy: a review of 50 cases from Jan 1987 to Aug 1990. J Obstet Gynecol India. 1991;45:490-3.

21. Bakshi S, Meyer BA. Indications for and outcomes of emergency peripartum hysterectomy. A 5-year review. J Reprod Med. 2000;45:733-7.

22. Francois K, Ortiz J, Harris C, Foley MR, Elliott JP. Is peripartum hysterectomy more common in multiple gestations? Obstet Gynecol. 2005;105:1369-72.

23. Allahabadia G, Ambiye V, Vaidya P. Obstetric emergency. A review of 50 cases from Jan 1987 to August 1990. J Obstet Gynecol India. 1990:41:634-7.

Cite this article as: Kamble SN, Jamdade YM.

Obstetric hysterectomy: a retrospective study. Int J Reprod Contracept Obstet Gynecol 2021;10:4522-6. 